\title{
O Cardiologista deve Suspeitar mais das Disfunções Tireoidianas!
}

\author{
Angelo V. A. de Paola, Cláudio Cirenza e Rui M. B. Maciel \\ São Paulo, SP
}

Apesar de apresentar farmacocinética complexa e efeitos colaterais no pulmão, tireóide, pele e sistemas digestivo e neurológico, fatos geradores de controvérsias frequentes na sua utilização, a amiodarona estabeleceu-se, a partir de 1976, como uma das drogas mais utilizadas para o controle da maioria das arritmias cardíacas ${ }^{1}$.

A administração de amiodarona causa inúmeras modificações na função da tireóide, que incluem alterações na síntese, no metabolismo e na ação dos hormônios da tireóide, a tiroxina (T4) e a triiodotironina (T3 $)^{2,3}$. A amiodarona é um derivado benzofurano com estrutura semelhante ao T3, com $37 \%$ de seu peso molecular constituído por iodo. Como cerca de $10 \%$ da droga, administrada em doses variáveis de 200 a 600 mg, é desiodada diariamente, os pacientes recebem 7 a $21 \mathrm{mg}$ de iodeto/dia, o que causa uma ingesta excessiva de iodo ao longo do tempo; além disso, a amiodarona inibe a enzima 5 '-desiodase tipo I, responsável pela conversão do pró-hormônio T4 no hormônio ativo, o T3, nos diversos tecidos do organismo, assim como inibe a entrada de T4 nos tecidos. Estes mecanismos contribuem para a elevação dos níveis séricos de T4 e diminuição de T3 nos pacientes eutireoidianos que recebem amiodarona a longo prazo ${ }^{2}$. Quando a dose administrada é > 400 mg, também ocorre elevação do hormônio estimulador da tireóide (TSH), por inibição da enzima 5 '-desiodase tipo II, que promove a conversão de T4 em T3 na hipófise. Além desses efeitos nos testes de função, a amiodarona também tem efeitos diretos citotóxicos na tireóide, o que causa o escape do T4 pré-formado na glândula para a circulação, fato que contribui também para a elevação sérica do T4. Finalmente, pela sua estrutura semelhante ao T3, a amiodarona e seus metabólitos podem ligarse aos receptores de T3 que atuam no DNA, aumentando ou inibindo a expressão de diversos genes e apresentam efeito antagonista da ação do T3 em órgãos como o coração, promovendo um efeito símile ao hipotireoidismo ${ }^{2-4}$.

Apesar das alterações dos testes de função tireodiana serem comuns à maioria dos pacientes que recebem amiodarona, a incidência de disfunção tireodiana induzida por amiodarona é bastante variável ${ }^{2,3}$, resultando de diferentes critérios diagnósticos utilizados para caracterizar as alterações tireodianas, da dose de amiodarona e da quantidade de iodo ofertado na dieta à população

Escola Paulista de Medicina, Universidade Federal de São Paulo. Endereço para Correspondência: Dr. Angelo A. de Paola - Escola Paulista de Medicina - Rua Botucatu - 740 - 04023-062 - São Paulo - SP E-mail - depaola@ cardiol.br

Recebido para Publicação em maio/04

Aceito em maio/04 estudada. A incidência de disfunção tireodiana induzida por amiodarona relatada pela literatura varia de 2 a $24 \%$, com a maioria dos artigos variando de 14 a 18\%; a tireotoxicose induzida por amiodarona é mais frequente em áreas deficientes de iodo, enquanto que o hipotireoidismo induzido por amiodarona é mais frequente nas áreas com ingestão suficiente de iodo ${ }^{2}$. Dessas difunções, 0 hipotireoidismo induzido por amiodarona é fácil de tratar, bastando a introdução do T4 se a amiodarona não puder ser retirada, enquanto que a tireotoxicose induzida por amiodarona é um desafio terapêutico ${ }^{5}$.

Neste número dos Arquivos Brasileiros de Cardiologia, Fuks e cols. $^{6}$ apresentam trabalho que demonstra prevalência elevada de disfunção tireodiana em pacientes da cidade do Rio de Janeiro tratados com amiodarona e revela grande divergência no comportamento dos cardiologistas relativamente ao acompanhamento desses pacientes; a disfunção tireodiana foi caracterizada por alterações do TSH, independentemente de manifestações clínicas ou outras alterações laboratoriais. Pacientes que já possuíam diagnóstico de hiper ou hipotireoidismo foram excluídos. A prevalência da disfunção tireoidiana laboratorial de 33,9\% encontrada nesse estudo foi elevada, principalmente levando-se em consideração que a dose média diária utilizada de amiodarona não foi alta.Metaanálise capaz de identificar efeitos adversos clínicos resultantes da utilização de doses baixas de amiodarona ( $<400 \mathrm{mg} / \mathrm{dia}$ ) relatou que a incidência de hipo ou hipertiroidismo clinicamente evidentes foi quatro vezes maior com a amiodarona quando comparado com o grupo placebo 7 . Entretanto, a incidência de disfunção tireoidiana de apenas 3,7\% (grupo placebo $=0,4 \%$ ), foi bastante inferior ao desta publicação que, além de importantes alterações laboratoriais, conseguiu identificar $7(12,5 \%)$ pacientes com disfunção clinicamente evidente.

A maior incidência de disfunção laboratorial tireodiana encontrada neste artigo deve-se, provavelmente, à utilização da alteração do TSH como critério diagnóstico, de acordo com as recomendações recentes das diversas sociedades internacionais de tireóide ${ }^{8}$. Essa preocupação é decorrente de dados que indicam mortalidade aumentada por doença cardiovascular em pacientes idosos com TSH diminuído, decorrentes provavelmente de arritmias cardíacas, especialmente de fibrilação atrial ${ }^{9-11}$. No Brasil, especialmente, essa preocupação é maior, pois como os preparados de T4 e T3 não exigem receita médica, a prevalência de indivíduos com TSH diminuído por tireotoxicose derivada de sua ingestão é maior que em outros lugares ${ }^{11}$. Uma possível explicação para a alta incidência de disfunção clínica pode ser decorrente da amostra ter pacientes mais suscetíveis para o desenvolvimento de alterações da tireóide, como a presença de alterações auto-imunes. Anticorpos anti- 
tireóide encontrados em $9 \%$ dessa amostra estiveram relacionados aos pacientes que apresentaram disfunção, sendo que $70 \%$ dessa população pode desenvolver hipotireoidismo ${ }^{12}$. Outra explicação é derivada do fato dos cardiologistas não analisarem, de modo sistemático, a função tireodiana enquanto tratam de seus pacientes com amiodarona.

Nesse estudo a disfunção tireoidiana foi mais freqüente em homens que em mulheres $(44 \% \times 26 \%)$ e essa diferença seria significante com o dobro do tamanho amostral. Esses achados são diferentes de estudos prévios, que relatam que o sexo feminino é um fator de risco para o desenvolvimento de disfunção tireoidiana na vigência da terapêutica com amiodarona. Essas questões clínico-laboratoriais levantadas pelo autor valorizam importantemente este manuscrito, indicando a necessidade de estudos mais abrangentes em nosso meio, onde a prescrição de amiodarona é bastante utilizada para o tratamento de diferentes arritmias cardíacas. Recentemente, evidenciamos, em área de ingestão normal de iodo, que o tratamento com amiodarona pode ser continuado em pacientes com cardiopatia chagásica, mesmo naqueles que desenvolvam disfunção tireodiana ou bócio num estudo que comparou 72 pacientes com cardiopatia chagásica recebendo o medicamento por $11 \pm 5$ anos com 33 pacientes que não o receberam: dos 72, apenas 26 mantiveram o TSH normal num seguimento de $9 \pm 5$ anos, enquanto que 24 o apresentaram elevado, 4 diminuído e 18 com flutuação, mas a maioria permaneceu clinicamente eutireodiana sem evidência de cardiopatia induzida por disfunção tireodiana ${ }^{13}$. A mesma recomendação não se aplica a áreas com deficiência de iodo, onde há o desenvolvimento de um maior número de casos de tireotoxicose induzida por amiodarona ${ }^{14}$.

Outra informação fundamental desse estudo é a observação que os cardiologistas em nosso meio, apesar de informados sobre a disfunção da tireóide induzida por amiodarona (cerca de 95\% responderam conhecer a informação), avaliam muito pouco a função tireoidiana sistematicamente antes $(17,5 \%)$ e durante $(50 \%)$ a terapêutica com amiodarona, inferindo-se que provavelmente na prática clínica diária, o diagnóstico de disfunção tireodiana é subestimado. Surpreendentemente, também é a informação que os mesmos médicos suspendem a droga em $80 \%$ dos casos, na vigência do diagnóstico de disfunção. Apesar desta conduta ser apropriada para os casos de tireotoxicose, a correta reposição dos hormônios tireoidianos permite a manutenção do medicamento nos pacientes hipotireoidianos com necessidade da manutenção da droga2-4.

Essas observações originais trazidas por Fuks e cols., além de enriquecerem os dados relacionados à esta importante situação clínica, delineam claramente a necessidade de estudos em nosso meio para a definição de estratégias diagnósticas e terapêuticas mais adequadas nesta importante situação clínica.

\section{Referências}

1. Rosenbaum MB, Chiale PA, Halpern MS, et al. Clinical efficacy of amiodarone as an antiarrhythmic agent. AmJ Cardiol 1976; 38: 934-944.

2. Martino $E$, Bartalena $L$, Bogazzi $F$, Braverman LE. The effects of amiodarone on the thyroid. Endocr Rev 2001; 22:240-254.

3. Klein I, Ojamaa K. Thyroid Hormone and the cardiovascular system. N EngJ Med 2001;344:501-509.

4. Bogazzi F, Bartalena L, Gasperi M, B raverman LE, Martino E. The various effects of amiodarone on thyroid function. Thyroid 2001; 11: 511-519.

5. Bartalena L, Bogazzi F, Martino E. Amiodarone-induced thyrotoxicosis: a difficult diagnostic and therapeutic challenge. Clin Endocrinol 2002; 56: 23-24.

6. Fuks AG, Vaisman M, Buescu A. Disfunção tireoidiana e conduta dos cardiologistas em pacientes utilizando amiodarona Arq Bras Cardiol 2004;82: 523.

7. Vorperian VR, Havighurst TC, MIler S, J anuary CT. Adverse effects of low dose amiodarone: A Meta-Analysis. J Am Coll Cardiol 1997;30:791-8.

8. Demers LM, Spencer CA. Laboratory medicine practice guidelines: laboratory support the diagnosis and monitoring of thyroid disease. Clin Endocrinol 2003; 657-658.

9. Sawin C, Geller A, Wolff P. Belanger AJ, et al. Low serum thyrotropin concentrations as a risk factor for atrial fibrillation in older persons. N Engl J Med 1994; 331: 1249-1252.
10. Parle JV, Maisonnneuve P, Sheppard MC, Boyle P, Franklyn J A. Prediction of allcause and cardiovascular mortality in elderly people from one low serum thyrotropin result: a 10-year cohort study. Lancet 2001; 358: 861-865.

11. Osman F, Gammage MD, Sheppard MC, Franklyn J A. Cardiac dysrhythmias and thyroid dysfunction: the hidden menace? J Clin Endocrinol Metab 2002; 87 : 963-967.

12. Maciel RMB. Avaliação laboratorial da função tireodiana, in "Glândulas Tireóide e Paratireóide: abordagem clínico-cirúrgica", editado por MB de Carvalho, Editora Atheneu, São Paulo, 2004, pp. 354-384.

13. Martino E, Aghini-Lombardi F, Bartalena L, et al. Enhanced susceptibility to amiodarone-induced hypothyroidism in patients with thyroid autoimmune disease. Arch Intern Med 1994; 26: 154: 2722-6.

14. Silva J R, Guariento ME, Fernandes GA, Maciel RMB, Ward LS. Impact of longterm administration of amiodarone on the thyroid function of patients with Chagas' disease. Thyroid 2004; 14: 373-379.

15. de Barros MA, Maciel RMB. Prospective study of the effects of amiodarone on thyroid function in Chagasic patients in an area of iodine deficiency. Rev Soc Bras Med Trop 1994; 27: 149-155. 